\title{
Environmental Assessment Tools: Toward an Interlinked Sustainable Design of Cities and Buildings. The Cases of Vado Ligure and Altare Municipalities
} (Italy)

\author{
Adriano Magliocco \\ Architecture and Design Department, Polytechnic School, University of Genoa, Italy \\ E-mail: magliocc@arch.unige.it
}

Katia Perini

Architecture and Design Department, Polytechnic School, University of Genoa, Italy

Chiara Piccardo

Architecture and Design Department, Polytechnic School, University of Genoa, Italy

Received: February 15, 2017 Accepted: March 17, 2017

doi:10.5296/emsd.v6i1.10727ＵRL: https://doi.org/10.5296/emsd.v6i1.10727

\begin{abstract}
The present paper aims at highlighting the connections between the environmental assessment of urban planning and building design activities at different scales. Environmental assessment is a multi-scale and inter/trans disciplinary process, which considers the city through an ecological approach. Environmental assessment includes different tools depending on the planning and design phase, with links and overlaps but also with contradictions. Four different evaluation fields are discussed - land use, water management, local resources, energy - also concerning the case of two Environmental Reports for Strategic Environmental Assessment (SEA) processes of municipal urban plans for two Italian municipalities, Vado Ligure and Altare. The analysis of case studies shows that SEA is not always an effective tool for strategic urban planning, as it includes similar assessment criteria to building scale ones, causing overlaps and contradictions.
\end{abstract}

Keywords: Strategic Environmental Assessment, Building Environmental Assessment, Land 
use, Water Management, Renewable Energy Resources, Local Materials

\section{Introduction}

Environmental assessments can be used to evaluate the impacts of an artefact or a transformation process on a specific territory, compared to the principles of environmental sustainability institutionally identified (Bond et al. 2012). This concept, while retaining sectoral connotations, is common to several different fields. Environmental assessment is an interdisciplinary process, both in an epistemological and scientific view (Obermeister, 2017). It is also an inter-scale process that can involve different disciplines operating at different scales (urban planning, technology, morphological design, etc.), as it will be shown in this paper. This implies the need to challenge environmental assessment processes and instruments continuously, in order to meet advances in technical standards, building technologies and urban strategies.

The concept of environmental assessment implies an ecological approach for territory transformation (Marzluff, J.M. et al., 2008). It takes into account different aspects related to the need for maintenance or recovery of an environmental equilibrium undermined by increasingly intrusive presence of man, determining the quality of the same environment in which man lives (in terms of physical and chemical characteristics, useful to our survival).

Assessment processes are based on the ability to measure - in a quantitative and qualitative way - through relevant indicators, the performance of a process or of an object (e.g. a building) with respect to predefined principles. Environmental assessment processes may have different purposes and therefore different outcomes, depending also from the challenges of our society (Retief et al., 2016). This approach can be used to approve or reject plans significantly affecting territories and communities (as in the case of the Environmental Impact Assessment, EIA, from the DIR 85/337/CEE to the DIR 2014/52/UE). It can be used also to compare the environmental quality of alternative land use solutions (as in the case of the Strategic Environmental Assessment process, SEA, DIR 2001/42/CE). Another example is life cycle assessment (LCA), which allows comparing products and services. Also building design choices can be evaluated, according to specific criteria aimed at reducing its environmental impact, as in the case of Green Building (GB) certification systems, LEED Leadership in Energy and Environmental Design, BREEAM Building Research Establishment Environmental Assessment Method, ITACA Protocol etc..

Worth mentioning that an evaluation process should not be a step up control - though often, instrumentally, it is; it should be integrated with the design process in different phases, in a circular way, with a strategic role (Noble, Nwanekezie, 2016). Assessment processes involve scientifically shared indicators (Donnelly et al., 2007), able to detect the effects of a specific phenomenon. Thus, same environmental assessment issues are considered in different phases of the building process, using different indicators or giving different meanings to the same indicators. Some examples of issues to be assessed in different phases of urban planning and building design process can be provided. These two levels of evaluation are interrelated even if they require different levels of detail and duration. 
In the present paper some examples are reported and discussed. These are based on two cases of Strategic Environmental Assessment (SEA) for the urban plans of two municipalities: Altare (about 2.000 inhabitants on 11,74 Kmq) and Vado Ligure (about 8.336 inhabitants on 23,38 Kmq) in the Province of Savona (Liguria Region, Italy); two municipalities with a vast territory with a low level of urbanization, with scattered houses, once part of horticultural areas; the urban body is dense and is occupied by residential and industrial activities (partly held for sale). Relevant fields are selected, i.e. Land use, Water management Renewable energy sources and Local resources, since they particularly affect planning and design at a range of scales. The aim is to discuss the connections between environmental assessment tools at different scales. Therefore the study compares the assessment methods and criteria of GB certification systems with the assessment outputs from the studied SEAs, with particular attention to the specific fields mentioned above. In regard to GB certification systems, the study focuses on two multicriteria-based tools, LEED and ITACA Protocol for residential buildings, which represents common schemes in Italy.

\section{Results and discussion}

\subsection{Land use}

Land use has a major impact on various environmental and ecological issues; land's specific features have to be carefully considered, physical-chemical characteristics, local climate, and also the presence of infrastructures and built areas. Identifying land uses is among the most relevant planning activities.

Changing land use might cause relevant impacts on its quality and on ecosystem services provision. Terrestrial ecosystems provide a number of vital services for people and societies, such as biodiversity, food, fibre, water resources, carbon sequestration, and recreation. Changes in socio-economic characteristics, land use, biodiversity, atmospheric composition and climate can affect the capacity of ecosystems to guarantee these services (Metzger et al., 2006). The impact of land use change on emissions, sequestration, and albedo also plays an important role in radiative forcing and in the carbon cycle (Fisher et al., 2007).

Urban areas depend on a healthy natural environment that continuously offers a range of benefits (Derkzen et al., 2015); ecosystem services include drinking water, clean air, healthy food, and protection against floods, also moderate air pollution, noise and heat stress, fundamental for human well-being (TEEB, 2011).

The importance of land use change is confirmed by the European Environmental Agency "Land is a finite resource: how it is used constitutes one of the principal reasons for environmental change, with significant impacts on quality of life and ecosystems, as well as on the management of infrastructure" (European Environment Agency, 2008).

In order to reduce land use change and the emissions connected to transportation needs and building energy use, compact development, compared with suburban lifestyles, can be more effective (Hamin and Gurran, 2009). In fact, a denser urban settlement potentially minimise transport demand, connecting population to existing built areas to concentrate human-related activities. Such design strategy allows protecting underdeveloped and sensitive lands and 
maintaining viable habitats in other areas (Farr, 2008).

Within environmental assessment systems at the building scale, quality indicators evaluate the re-use of urbanized areas, with nearby infrastructure and networks (water, gas, electricity, sewer, etc.), and presence of public transportations, while natural and farming areas receive a negative score. LEED v4 credits related to land use are considered among "Location and transportation" and "Sustainable sites". In the first category, in addition to transport-related credits, also "Sensitive Land Protection" and "High Priority Site" are included. In the second, the most relevant credits for this issues are: "Site Assessment" which encourages early analysis of site conditions to inform design and "Site Development - Protect or Restore Habitat" (USGBC, 2013).

Italian ITACA Protocol favours the reuse of already urbanized areas with a preference for the polluted areas to be reclaimed (Prassi di Riferimento UNI/PdR 13:2015, SHEET a.1.5), while the Italian association Bioarchitettura ${ }^{\circledR}$ system believes that the polluted areas are not suitable for a wealth living environment (sheet A.1.1).

Site selection for a project should be part of a planning process developed according to local and regional regulations. In the case of the Environmental Assessment of Vado Ligure, ecosystem aspects are specifically considered in order to minimize the impact on animal biodiversity. Other important aspects related to the land characteristics in terms of slope stability or instability, hydrology and seismic issues. In the case of the Environmental Assessment of Altare, hypothesis of densification and redevelopment of urban areas made it possible to implement to zero soil consumption planning. In both cases ecological network elements have been considered, e.g. ecological corridors, natural habitats and wild fauna and flora. In the areas affected by natural values, human impact is not increased. Thus, maps have been drafted in order to control planning strategies compared to the natural values identified (using Liguria Region monitoring data).

\subsection{Water Management}

Water management is a major issue especially in urban areas, since rainfall on the hard surfaces (e.g. asphalt and concrete) of built-up areas cannot be absorbed and it runs off through drainage systems into rivers. In cities, in order to process high amount of water, rain water and waste water from residential, industrial, etc. uses, water infrastructure is in most of the cases designed as a linear system, which results in ecological vital functions impoverishment (Walsh et al., 2005). Flooding can be a consequence when river banks cannot cope with the influx (Perini and Sabbion, 2017). Differently, the majority of precipitation falling on natural land is absorbed by soil to join afterwards the water table or absorbed by vegetation and transpired back into the atmosphere (Dunnett and Kingsbury, 2008). According to Scholz-Barth (2001), about $75 \%$ of rainfall on towns and cities is lost directly as surface runoff as compared to around five percent on a forested area. Water quality is another major issue in urban areas, since polluted stormwater runoff affects the quality of urban waters, due to industrial discharges, mobile sources, residential and commercial wastewater, etc. (EPA, 2016). 
The European legislation, in particular the Framework Directive 60/2000 (European Parliament, 2000) and in the Directive on the Protection of Underground Waters (2006/118/EC), regulate management policies on drinking water, bathing, surface and groundwater, water alteration control. Environmental quality standards are defined as well as trends of deterioration/recovery of water bodies. According to the EU framework, water quality should be improved according to specific objectives, related to ecological and chemical aspects of surface waters.

When speaking about urban planning and building design, specific attention should be paid to sewage disposal, to reduce the amount of water. This can be achieved thanks to several strategies: e.g. the reduction of water use and the recycle of disposal water (both grey although with some difficulties arising from sanitary issues - and white waters). Recycled disposal water can be used for several non drinking purposes (e.g. watering of vegetation; Giachetta and Magliocco, 2007).

Environmental assessment systems for buildings include criteria and indicators to reduce the water disposal, assuming the possibility to treat the water directly in situ. Rating systems as LEED also consider the integration of green roofs, green areas, porous paving and other green infrastructure for stormwater management. LEED v4, for the credit "rainwater management (in "Sustainable sites"), suggests the use green infrastructure (GI) and low impact development (LID) rainwater management techniques on site, with the metric "total volume of runoff calculated for the 95th percentile of regional or local storm events". Also in the category "Water efficiency", indoor and outdoor water use reduction" are prerequisites, as well as "Building- Level Water Metering", i.e. each project to be capable of measuring whole building water use. LEED v4 also encourages the analysis of water source and the maximization of water cycles, submetering at least two water end uses (USGBC, 2013).

In the case of the Environmental Assessment of Vado Ligure, when urban planning includes the growth of settlements, particular attention is paid to the connection with existing infrastructure and its possible further development. In addition, a rule has been inserted to limit soil sealing of areas around the new buildings, according to the hydraulic invariance principle. In both SEA cases (Vado Ligure and Altare), the aqueduct authority has been asked to ensure that the availability of drinking water is guaranteed for new residents. The increase in the number of citizens was calculated on the basis of regional regulations ( 1 every 25 square meters of new buildings); the aqueduct then calculated the increase of drinking water needed, since it must ensure 250 litres per person per day. Nevertheless, it has been suggested water saving measures for new buildings (rainwater tanks, where possible). In particular, in Vado Ligure, the urban green Regulation identifies, as suitable vegetation species, only native species with low water requirements.

\subsection{Renewable Energy Sources}

In the framework of the EU climate policy for 2020, three main strategies are addressed to the built environment: energy efficiency, energy saving and the use of renewable energy sources (RES). 


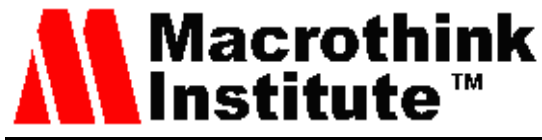

The EU Directive 2009/28/EC binds the member states to increase the energy production from renewable energy sources by 2020 in different energy sectors (e.g. industry, households and services), according to the national targets. The national policies increasing RES use concern energy consumption for electricity, heating/cooling and transportation in order to reduce greenhouse gas emissions. At the same time, the EU Directive 2010/31/CE aims at reducing energy consumption in the building sector, through the improvement of the energy performance of buildings to the nearly zero-energy standard, as well as through the share of energy from renewable sources.

In the last few years, the raising of the European and national energy targets have increased the role of cities (Klessman et al., 2011; Di Leo and Salvia, 2017), as underlined by different European initiatives, starting from the Aalborg Charter in 1994 to the Covenant of Mayors for Climate and Energy in 2008 and the promotion of the Sustainable Energy Action Plans (SEAPs). Therefore, urban planning can contribute to meet the EU directives, changing the local and territorial perception of energy availability and management.

Urban planning and sustainability evaluation tools, like Strategic Environmental Assessment, can identify opportunities for the development of renewable energy systems, also integrated in the built environment; at the same time, they can minimize the consumption of local resources and preserve natural and cultural landscapes. Indeed, it is necessary to ensure the sustainable development of renewables (Pang et al., 2014).

In 2010 Italy receipts the directive 2009/28/EC through the National Action Plan, which lay down the energy strategy to increase the share of renewable sources to $17 \%$ of national energy consumption by 2020. The National Action Plan also provides the direction for the Regional Energy and Environment Plans, that all the municipalities have to meet. In particular, the Energy and Environment Plan of Liguria focus on solar photovoltaic and wind energy, which represent the most important renewable sources of electricity. The plan further promotes the use of these two renewable energy sources, seeking to increase the solar photovoltaic energy from 8 ktep to $23 \mathrm{ktep}$ and the wind energy from 8 ktep to $43 \mathrm{ktep}$ by 2020, basing on 2012 energy production data (PEAR, 2104). This implies a great attention on land use and integration of RES technologies in the built environment.

In this regard, the SEA of Vado Ligure urban plan analyses and maps the actual solar energy potential of the municipal territory, especially considering the integration of photovoltaic and solar thermal panels into the existing buildings. For this reason, the analysis focuses on orientation, solar exposure and technological characteristics of the existing roofs. The purpose of the maps is to provide more detailed information on the local strategy of renewable energy use, in addition to the regional database and maps, but it is unlikely that they will come to find incentives for the installation of micro PV systems. In Altare, a new project for the installation of four wind turbines of 1.5 MW each has undergone regional EIA and is now under Province approval.

The energy issue also plays a significant role in GB certifications through the application of assessment criteria concerning both embodied energy of building materials and energy consumption for heating/cooling, hot water, lighting and household appliances during the 
operation stage of the building. In this regard, ITACA Protocol and LEED show different approaches, as described below.

- ITACA Protocol mainly refers to the existing national energy code for buildings and to the normative standards. For example, the calculation of the energy performance of the building envelope during the heating and cooling seasons refers to the minimum value of energy performance according to the national law. Furthermore ITACA Protocol also rewards the increase of the minimum standard by $20 \%$ or more, as well as the renewable energy production over $50 \%$ of the total energy consumption for heating.

- LEED lays down a pre-requirement concerning the use of ASHRAE norms or the use of a dynamic analysis of the building energy performance, alternatively, instead of the use of the technical standard UNI TS 11300. LEED also rewards the optimization of the energy performance of buildings, when increased of the minimum standard by $50 \%$ or more, as well as the renewable energy production over $1 \%$ of the total energy consumption in terms of costs.

- Both ITACA Protocol and LEED take into account $\mathrm{CO}_{2}$ emissions from energy consumption, but LEED provides a broader criterion, not only including the use of renewable energy technologies but also including the use of community systems and compensation projects of carbon dioxide.

Although GB certifications mainly provide indications for buildings or local urban projects, the application of the benchmarks can influence the urban development. Therefore, in a broader application of high-energy standards, especially concerning the use of RES, SEA can play an important role in balancing different synergic resources.

\subsection{Local Resources}

Most of the GB certification checklists include assessment criteria concerning environmental performance of building materials. These criteria usually regard several lifecycle environmental impacts of materials and resources used in new constructions and retrofitting. In this regard, they consider different environmental performance: from the sustainability of the supply chain (procurement, production and distribution), to the implementation of construction waste management, in order to reduce the material/resource consumption and the environmental impacts of their production process. The use of local resources is also supported by GB certification standards. First, it can reduce energy consumption and air pollutant emissions from transport of building materials. Secondly, the use of local resources can increase the demand for regional building materials that are extracted, harvested or recovered and manufactured near the construction site, in favour of the local economic development.

The use of local resources is fostered by both ITACA Protocol and LEED, even though different criteria are applied. Indeed, the concept of 'local' for building materials differs among rating systems. For example, building materials are 'local', according to ITACA, if the distance between the production and construction sites is less than $200 \mathrm{~km}$ (ITACA, 2015). Whereas building materials are 'local', according to LEED v4, if the distance between the 
extraction and production sites and the construction site is less than or equal to $160 \mathrm{~km}(800$ $\mathrm{km}$ in the previous versions), for a minimum of $25 \%$ of the total materials' cost (USGBC, 2013). Furthermore, LEED pays more attention to materials than ITACA Protocol, although it has a similar weight, resulting in significantly different scores (Asdrubali et al., 2015).

However, the use of local resources may be influenced by the local building codes and the regional regulations concerning the conservation and protection of the architectural, urban and landscape heritage. The Italian Code of Cultural Heritage and Landscape (legislative decree No. 42/2004) and the Regional Landscape Protection Plan of Liguria pursue the maintenance of the built heritage taking into account traditional building materials. Regional and local regulations usually support the use of local building materials, but difficulties in their application can occur. First, raw resources used in traditional buildings may not be available nearby anymore. For example, the urban plans of Altare include local landscape protection norms (in Italian, 'Disciplina Paesistica di Livello Puntuale') fostering the use of slate, which is a typical rock used as building covering and cladding in Liguria. Also the Liguria Regional House Plan (regional law No. 49/2009 and subsequent amendments), concerning the relaunch of requalification interventions on the building stock, allows additional building extensions if slate is used in retrofitted buildings. However, the regulatory framework does not take into account the effective availability and origin of slate. Although slate was extracted from regional mines in the past, the local slate mining is no longer economically sustainable.

Second, some local building products are not supported by regional regulations and building codes, because they are not considered traditional materials of the local architectural heritage, even though they can be procured in the region. For example, wood-based building products are not supported by regional regulation concerning architectural and landscape heritage, even though external cladding and finishing made of local timber would be available nearby and appreciated for their environmental performances (Piccardo, 2014; Wang et al., 2014; Asdrubali et al., 2017). In particular, in Liguria, as well as in other Italian regions, there is a small-scale timber production (12\% of sales by volume, Torreggiani and Mori, 2014) that could supply wooden building materials locally and could be valorised by local building regulations. For example, the municipality of Altare and Vado Ligure could encourage the use of wood-based building products through their master plans and building codes, as well as the SEA could blend the landscape protection requests and the needs of local economic development together.

In this regard, GB certification standards provide a benchmark that could be integrated in the local regulatory framework and planning. Moreover, wood materials and wood-based building products are able to satisfy a larger amount of check-listed environmental criteria in comparison with other building products. A comparative study of different GB certification standards (Piccardo, 2014) shows that using wood products in new constructions could account for 9 to $19 \%$ of the overall maximum score in GB certification. In particular, the use of wood-based building products could account for $10 \%$ and $11 \%$ of the maximum score of ITACA Protocol and LEED, respectively. Therefore, GB certifications take into great account building products from renewable sources, as described below. 
- ITACA Protocol assigns credits for the use of local material over $18 \%$ of the total material weight. Furthermore, the calculation methodology recommends multiplying factors to increase the weight of the local materials when the haulage distance is less than $200 \mathrm{~km}$. This criterion is synergic with other ones, when the building materials come from recycle, reuse or renewable sources.

- LEED provides different criteria concerning the use of materials from local and sustainable sources. It is important that building materials not only satisfy recommended haulage distances but also come from responsible procurement of raw materials, guaranteed by environmental product assessment. Therefore, LEED assigns credits when a share of building materials is certified through Environmental Product Declaration (at least 20 building materials from 5 different suppliers) or other ecolabels (50\% of material cost). The scheme also gives the opportunity to increase credits when LCA analysis of the building show that at least three impact categories are reduced by $10 \%$. Hence, as for ITACA Protocol, the LEED criterion concerning local materials is synergic with other ones.

In conclusion, the use of local resources is not consciously enhanced by the regional and local regulations, especially those concerning the conservation and protection of the architectural, urban or landscape heritage. Only in recent years, some local building codes have been providing sustainable design guidelines, as well as incentives, promoting the use of renewable sources and sustainable building materials, included wood-based materials. In particular, 446 Italian municipalities have adopted sustainable design guidelines, fostering building materials from local resources (ONRE 2013); in Liguria, the municipalities of Vezzano Ligure, Savona and Castelnuovo Magra.

\section{Conclusions}

Environmental assessment process shows links and overlaps and also contradictions, depending on the planning and design phase. Four different evaluation fields have been analyzed - land use, water management, local resources, energy - showing that different stages of evaluation are interdependent even if they develop on very different time frames.

Land use is considered during city planning and SEA process; however, building environmental assessment tools evaluate the site choice, creating overlapping and sometimes contradictions. During the SEA process, checking the availability of drinking water, especially willing to increase the number of citizens, is essential; such evaluation is made according to the potential of the reservoir that serves the aqueduct, according to a statistic per capita consumption. However, the consumption can vary with the water cycle managing at building scale (Water management), which is considered within environmental assessment systems. A better assessment might require consumption data. This could allow organizing information campaigns in order to improve private management of drinking water. It is known that the daily habits (e.g. leaving the tap running always while brushing) lead to significant waste water. The interaction between the two phases can therefore favour or disadvantage the increase of the possible inhabitants number. 
Renewable energy sources represent another inter-scalar theme. At the planning scale (SEA), it is necessary to identify the urban policies that allow the installation of renewable energy plants. Self-production is, however, generally run by national regulations and it becomes difficult for a municipality to identify incentives that are not in contradiction. The evaluation systems of buildings encourage the adoption of independent renewable energy plants. The convenience in their use depends, thus, especially on the degree of technological advance that makes them efficient and convenient or not. Political decisions and technological efficiency are strongly connected. Few municipalities provide incentives for distributed energy production, preferring to promote large-scale plants. This is also because the installation of microgeneration plants / RES technologies by household consumers / in individual homes and single buildings are strictly regulated by the national laws and it is considered unlikely that they can achieve higher energy-efficiency standards. Also, large plants can be cost effective for municipalities as companies pay charges for each MWh produced. In addition, wide spread of microgeneration plants might not have minor impacts compared to few large plants, especially considering urban landscape modification.

Last example of this paper is related to the use of local resources. Often, the use of locally extracted stones characterized the traditional architecture; the use of local stone both in building requalification and in the new constructions is an interesting element of continuity in architecture. Furthermore, use of local products reduces energy transport costs and, consequently, also the resulting emissions. Mining, however, is an element of irreversible land degradation and comes, in some cases, inhibited; heavy industry is a source of pollution: air, noise, etc. As this case shows, the environmental assessment, at different scales, could be contradictory. A problem is related to the general structure of evaluation system for buildings, as it has to be applied in different situations. SEA uses shared criteria of environmental protection, but the acceptability of the planning choices is defined in a discussion at the local level. In order avoid contradictions between the different levels of evaluation, assessment tools at the building scale should have a greater flexibility in determining the applicability of certain parameters. In this case, a list of exceptions should be defined according to which the use of a local material does not lead to positive feedback, e.g. where this is of limited availability or when its production has negative consequences on the territory. According to this principle, a report should accompany the evaluation.

\section{References}

Asdrubali, F., Baldinelli, G., Bianchi, F., \& Sambuco, S. (2015). A comparison between environmental sustainability rating systems LEED and ITACA for residential buildings. Building and Environment, 86, 98-108. https://doi.org/10.1016/j.buildenv.2015.01.001

Asdrubali, F., Ferracuti, B., Lombardi, L., Guattari, C., Evangelisti, L., \& Grazieschi, G. (2017). A review of structural, thermo-physical, acoustical, and environmental properties of wooden materials for building applications. Building and Environment, 114, 307-332. https://doi.org/10.1016/j.buildenv.2016.12.033

Bond, A., Morrison-Saunders, A., Pope, J. (2012). Sustainability assessment: the state of the art. Impact Assessment and Project Appraisal, 30(1), 53-62. 
https://doi.org/10.1080/14615517.2012.661974

Derkzen, M. L., van Teeffelen, A. J. A., \& Verburg, P. H. (2015). REVIEW: Quantifying urban ecosystem services based on high-resolution data of urban green space: an assessment for Rotterdam, the Netherlands. J. Appl. Ecol. 52, 1020-1032.

https://doi.org/10.1111/1365-2664.12469

Di Leo, S., \& Salvia, M. (2017). Local strategies and action plans towards resource efficiency in South East Europe. Renewable and Sustainable Energy Reviews, 68, 286-305. https://doi.org/10.1016/j.rser.2016.09.115

Donnelly, A., Jones, M., O'Mahony, T., \& Byrne, G., (2007). Selecting environmental indicator for use in strategic environmental assessment. Environmental Impact Assessment Review, 27, 161-175. https://doi.org/10.1016/j.eiar.2006.10.006

Donnelly, A., Jones, M., O'Mahony, T., \& Byrne, J. (2007). Selecting environmental indicator for use in strategic environmental assessment. Environmental Impact Assessment Review, 27, 161-175. https://doi.org/10.1016/j.eiar.2006.10.006

Dunnett, N., \& Kingsbury, N. (2008). Planting green roofs and living walls. Timber Press, Portland, Or.

EPA, U. (2016). US Environmental Protection Agency [WWW Document]. URL http://www3.epa.gov/ (accessed 2.12.16).

European Environment Agency (2008). Land use available online at http://www.eea.europa.eu/themes/landuse/intr.

European Parliament (2000). Directive 2000/60/EC of the European Parliament and of the Council of 23 October 2000 establishing a framework for Community action in the field of water policy.

Farr, D. (2008). Sustainable urbanism : urban design with nature. Wiley, Hoboken, N.J.

Fisher, B.S., Nakicenovic, N., Alfsen, K., Morlot Corfee, J., de la Chesnaye, F., Hourcade, J.-C., Jiang, K., Kainuma, M., La Rovere, E., Matysek, A., Rana, A., Riahi, K., Richels, R., Rose, S., van Vuuren, D., \& Warren, R. (2007). Issues related to mitigation in the long term context, In Climate Change 2007: Mitigation. Contribution of Working Group III to the Fourth Assessment Report of the Inter-governmental Panel on Climate Change [B. Metz, O.R. Davidson, P.R. Bosch, R. Dave, L.A. Meyer (eds)].

Giachetta, A., \& Magliocco, A. (2007). Progettazione sostenibile: dalla pianificazione territoriale all'ecodesign. Carocci, Roma.

Hamin, E. M., \& Gurran, N. (2009). Urban form and climate change: Balancing adaptation and mitigation in the U.S. and Australia. Habitat Int., 33, 238-245.

https://doi.org/10.1016/j.habitatint.2008.10.005

ITACA (2015). UNI/PdR 13.1:2015. Sostenibilità ambientale nelle costruzioni - Strumenti operativi per la valutazione della sostenibilità. Edifici residenziali. Available at 
http://www.itaca.org/documenti/news/uni_pdr_13_1_2016.pdf

Klessmann, C., Held, A., Rathmann, M., \& Ragwitz, M. (2011). Status and perspectives of renewable energy policy and deployment in the European Union. What is needed to reach the 2020 targets? Energy Policy, 39(12), 7637-7657. https://doi.org/10.1016/j.enpol.2011.08.038

Marzluff, J. M. et al. (2008). Urban Ecology An International Perspective on the Interaction Between Humans and Nature. SpringerMetzger, M.J., Rounsevell, M.D.A., Acosta-Michlik, L., Leemans, R., Schröter, D. (2006). The vulnerability of ecosystem services to land use change. Agric. Ecosyst. Environ, 114, 69-85. https://doi.org/10.1016/j.agee.2005.11.025

Noble, B., \& Nwanekezie K. (2016). Conceptualizing strategic environmental assessment: Principles, approaches and research directions. Environmental Impact Assessment Review, 62, 165-173. https://doi.org/10.1016/j.eiar.2016.03.005

Obermeister, N. (2017). From dichotomy to duality: Addressing interdisciplinary epistemological barriers to inclusive knowledge governance in global environmental assessments. Environmental Science \& Policy, 68, 80-86.

https://doi.org/10.1016/j.envsci.2016.11.010

ONRE (2013). L'innovazione energetica in edilizia. I regolamenti edilizi comunali e lo scenario dell'innovazione energetica e ambientale in italia. Rapporto ONRE 2013. Available at https://www.legambiente.it/sites/default/files/docs/sito_onre_2013_min.pdf

Pang, X., Mörtberg, U., \& Brown, N. (2014). Energy models from a strategic environmental assessment perspective in an EU context. What is missing concerning renewables? Renewable and Sustainable Energy Reviews, 33, 353-362.

https://doi.org/10.1016/j.rser.2014.02.005

PEAR (2014), Piano Energetico Ambientale Regionale 2014-2014, Liguria Region. Available at

http://www.ambienteinliguria.it/eco3/DTS_GENERALE/20141211/PEAR2014_2020definiti vo.pdf

Perini, K., \& Sabbion, P. (2017). Urban Sustainability and River Restoration: green and blue infrastructure, Construction Sustainability. https://doi.org/10.1002/9781119245025

Piccardo, C. (2014). Certificazioni ambientali degli edifici: il contributo del legno come materiale ecosostenibile [Environmental certification of buildings: the contribution of wood as sustainable building material]. Legnoarchitettura, 15, 89-95.

Retief, F., Bond, A., Pope, J., Morrison-Saunders, A., \& King, N. (2016). Global megatrends and their implications for environmental assessment practice. Environmental Impact Assessment Review, 61, 52-60. https://doi.org/10.1016/j.eiar.2016.07.002

Scholz-Barth, K. (2001). Green Roofs: Stormwater Management From the Top Down. Environ. Des. Constr. Feature January/February 2001.

TEEB (2011). TEEB Manual for cities: ecosystem services in urban management, in: UNEP 
and the European Union (Ed.), The Economics of Ecosystems and Biodiversity. Manual for Cities: Ecosystem Services in Urban Management.

Torreggiani, M., \& Mori, P. (2014). Rapporto sullo stato delle foreste in Liguria 2011-2013, Edizione Compagnia delle foreste, Arezzo.

USGBC (2013). LEED v4 User Guide (Updated November 2014). Available at http://www.usgbc.org/resources/leed-v4-user-guide

Walsh, C. J., Roy, A. H., Feminella, J. W., Cottingham, P. D., Groffman, P. M., \& Morgan, I. R. P. (2005). The urban stream syndrome: Current knowledge and the search for a cure. $J$. North Am. Benthol. Soc. 24, 706-723. https://doi.org/10.1899/04-028.1

Wang, L., Toppinen, A., \& Juslin, H. (2014). Use of wood in green building: a study of expert perspectives from the UK. Journal of Cleaner Production, 65, 350-361.

https://doi.org/10.1016/j.jclepro.2013.08.023

\section{Copyright Disclaimer}

Copyright for this article is retained by the author(s), with first publication rights granted to the journal.

This is an open-access article distributed under the terms and conditions of the Creative Commons Attribution license (http://creativecommons.org/licenses/by/3.0/). 